\title{
Mechanical and antibacterial properties of a nanocellulose- polypyrrole multilayer composite
}

\author{
Benoit Bideau¹, Julien Bras ${ }^{2}, 3$, Seema Saini², 3, Claude Daneault", Eric Loranger ${ }^{1 *}$ \\ 1. Lignocellulosic Material Research Center, Université du Québec à Trois-Rivières, 3351 boul. des Forges, C.P. 500, \\ Trois-Rivières, QC, G9A 5H7, Canada \\ 2. Univ. Grenoble Alpes, LGP2, F-38000 Grenoble, France ${ }^{1}$ \\ 3. CNRS, LGP2, F-38000 Grenoble, France
}

Benoit.bideau@uqtr.ca

Julien.bras@pagora.grenoble-inp.fr

Seema.Saini@1gp2.grenoble-inp.fr

Claude.daneault@uqtr.ca

Eric.Loranger1@uqtr.ca

\begin{abstract}
In this study, a composite film based on TEMPO-oxidized cellulose nanofibers (TOCN), polyvinyl alcohol (PVA) and polypyrrole (PPy) was synthesized in situ by a chemical polymerization, resulting in the induced absorption of PPy on the surface of the TOCN. The composite films were investigated with scanning electron microscopy, thermogravimetric analysis, contact angle measurements, mechanical tests, and evaluation of antibacterial properties. The developed composite has nearly identical Young modulus (3.4 GPa), elongation (2.6\%) and tensile stress (about $51 \mathrm{MPa}$ ) to TOCN even if PPy, which as poor properties by itself, was incorporated. From the Energy-dispersive X-ray spectroscopy (EDX) results, it was shown that PPy is mainly located on the composite surface. Results confirmed by an increase from 54.5 to $83^{\circ}$ in contact angle, an increased heat protection (Thermogravimetric analysis) and a decrease in surface energy. The nanocomposites were also evaluated for antibacterial activity against bacteria occasionally found in food: Gram-positive Bacillus Subtilis (B. Subtilis) and Gram-negative bacteria Escherichia Coli (E. Coli). The results indicate that the nanocomposites are effective against all of the bacteria studied as shown by the decrease of $5.2 \log$ Colony Forming Unit (CFU) for B. Subtilis and $6.5 \log$ CFU for E. Coli. Resulting in the total destruction of the studied bacteria. The perfect match between the resulting inhibition zone and the composite surface area has demonstrated that our composite was contact active with a slight leaching of PPy. Our composite was successful as an active packaging on meat (liver) as bacteria were killed by contact, thereby preventing the spread of possible diseases. While it has not been tested on bacteria found in medicine, TOCN/PVA-PPy film may be able to act as an active sterile packaging for surgical instruments.
\end{abstract}

Keywords: Polypyrrole, nanofibers cellulose, antibacterial, mechanical, composite

\section{INTRODUCTION}

During the last decade, conjugated polymers such as polyaniline (PANI), polythiophene (PTh), polypyrrole (PPy), polyfuran $(\mathrm{PFu})$, poly(p-phenylene vinylene) (PpPV) and poly(acetylene) (PAc) have been the focus of research in science and technology. The main goals of these studies are to use the polymers' high variety of physical and electro-conductive properties as semiconductors and electroactive materials for application in batteries, molecular electronic devices, sensors, solid phase extractions, light emitting diodes, etc. ${ }^{1,2,3}$. Among the conducting polymers, particular interest has been focused on PPy because of its high electrical conductivity, ease of synthesis, good environmental stability and biocompatibility. ${ }^{4}$ Furthermore, PPy is also known to kill bacteria. ${ }^{5} 6$ Based on these studies, we considered using PPy to achieve a suitable composite for a new type of packaging.

PPy can be synthesized by chemical oxidation or electrochemical polymerization of pyrrole in an aqueous solution. ${ }^{7}$ The chemical oxidative polymerization of PPy requires an oxidant such as ferric chloride, potassium dichromate, or ammonium persulfate. ${ }^{8}$ However, the applications of PPy remain very limited because of poor mechanical properties. ${ }^{9}$ Several studies have been conducted to improve the physical properties through the production of composite materials containing PPy. ${ }^{10}$

The incorporation of PPy into natural polymers can enhance the physical and chemical properties of both the 'host' and the 'guest'. Recently, experimental studies have focused on different types of natural polymers such as cellulose, dextrin, and chitosan. ${ }^{4,11-13}$ Among them, cellulose has been the subject of numerous studies. ${ }^{14,15}$ Conducting composites of PPy/cellulose with high Galvano static cycling stability have been developed for use in flexible energy devices, such as batteries, higher thermal stability in nanofibrous membrane, enhanced ion absorption capacity and adjustable electrochemical properties. ${ }^{16,17}$ Thus, numerous studies using flexible and light-weight composites of cellulose substrates derived from Cladophora sp. algae and PPy were obtained by the chemical polymerization of pyrrole. These PPy/cellulose composites are highly porous and can be used as electrode materials in environmentally friendly charge storage devices. ${ }^{18}$ However, coating substances with PPy remains a challenge, as it is not easy to control the agglomeration of conjugated polymer, and the polymer chains are prone to deposit as irregular nanoparticles or sediments. Influence of the cellulose substrate ${ }^{19}$ and the synthesis conditions ${ }^{20}$ directly affect the composite properties and morphology.

\footnotetext{
* Corresponding author. Tel.: +1 819 376-5011 ext 4518

E-Mail address: Eric.loranger1@uqtr.ca (E.Loranger)
} 
Cellulose is extracted from biomass and is the most abundant organic polymer on Earth. The component is inexpensive, relatively easy to process, renewable, biodegradable and biocompatible. During recent decades, interest in nanoscale cellulose has increased; among them, nano-fibrillated cellulose (NFC) prepared by high shear mechanical treatment of cellulose fibers. ${ }^{21}$ The diameter of NFC ${ }^{22}$ ranges from approximately 5 to 50 nanometers. Typically, the size depends mainly on the production process. Different pretreatment processes for producing NFC currently exist, ${ }^{23}$ such as enzymatic pre-treatment, ${ }^{24}$ powerful fibrillation using grinding, ${ }^{25}$ TEMPO oxidation ${ }^{26}$ and sonocatalysed TEMPO oxidation. ${ }^{27,28}$ Once dried, the NFC suspension produces a film, or "Nano paper," which presents a good barrier ${ }^{29}$ and high mechanical properties. ${ }^{30}$ Grafting the NFC has demonstrated promising results with at least a bacteriostatic effect or a bactericidal property. ${ }^{31}$

However, in most research, such NFC has been used as a binder for conjugated polymers such as PPy, ${ }^{32} \mathrm{PANI}^{33}$ or carbon nanoparticles, ${ }^{34}$ but none of these nanocomposites have been used for antibacterial applications. Recently, a small part of one study ${ }^{35}$ has suggested antibacterial properties of a NFC/PPy-silver composite against Gram-positive bacteria by inhibition zone testing. However, the study clearly demonstrates that the antibacterial character was from the presence of silver incorporated in the composite rather than the PPy. It is also important to note that the use of silver nitrate, a relatively expensive oxidant, in the polymerized composite may provide an antibacterial solution, but at a high cost. The need to provide similar properties at a lower cost are obvious. Meanwhile, a nano-conductive composite of PPy/Dextrin obtained via in situ polymerization was evaluated for antibacterial activity against Gram-positive and Gram-negative bacteria with interesting results. ${ }^{3}$ Most of these organisms can cause severe infections in humans and have the ability to survive in severe conditions due to their adaptation to multiple environmental habitats. Therefore, it has become a major worldwide challenge to limit the development of diseases. ${ }^{36}$ Thus, many projects are now focusing on the development of polymeric ${ }^{37}$ or natural ${ }^{38,39}$ materials with antimicrobial activity. Although chitosan is known for its antibacterial properties, combination with other active molecules (gold nanoparticles or quaternary phosphonium) improves the antibacterial composite character. ${ }^{40}$ Moreover, a low cytotoxicity and a biocompatibility of these biocomposites allows for the consideration of biomedical application.

The main goal of the current study was to synthesize multilayer composite films that were obtained via in situ polymerization of pyrrole on the surface of the film with an inexpensive oxidant, with iron chloride TOCN and polyvinyl alcohol (PVA) added as a reinforcement agents. In addition, this work was also aiming to highlight the antibacterial properties of PPy against Grampositive and Gram-negative bacteria and demonstrate a potential application for active sterile packaging.

\section{MATERIALS AND METHODS}

\subsection{Materials}

Pyrrole $\left(\mathrm{C}_{4} \mathrm{H}_{5} \mathrm{~N}\right)$, iron (III) chloride $\left(\mathrm{FeCl}_{3}\right)$, PVA (Mw 146,000-186,000, 98-99\% hydrolyzed), formamide and 1-

bromonaphthalene were purchased from Sigma Aldrich and used as received. A commercial never-dried bleached Kraft wood pulp was used as the cellulose sample for the production of TOCN through TEMPO oxidation and sonication treatments. ${ }^{28}$ The average width and length of the nanofibers were approximately $3.5 \pm 1.0$ and $306 \pm 112 \mathrm{~nm}$, respectively, but a small proportion of microfibrillated cellulose was still present. The carboxyl content expressed in mmol $/ \mathrm{kg}$ was estimated at 1600 and the degree of polymerization was estimated at approximately 200. Escherichia coli ATCC 10536 (E. Coli) and Bacillus subtilis DSM 618 (B. Subtilis) were provided by Zellkulturen GmbH (German Collection of Microorganisms and Cell Cultures) and Humeau (France).

\subsection{Methods}

\subsubsection{Preparation of composite}

PPy powder: Pure PPy was synthesized by mixing $1 \mathrm{ml}$ of pyrrole with $10 \mathrm{ml}$ of $\mathrm{FeCL}_{3}$ solution at $0.3 \mathrm{M}$. The reaction lasted $30 \mathrm{~min}$, after which the solid residue was collected with a Buchner funnel and thoroughly washed with distilled water before it was air dried on a petri.

TOCN films: A solution of TOCN $(50 \mathrm{ml})$ at $0.5 \%$ was prepared using a gel of TOCN at $2.6 \%$ and water. The mixture was thoroughly mixed until a homogenous medium was obtained. Next, the solution was poured in an aluminum dish of $90 \mathrm{~mm}$ to be oven dried for $1 \mathrm{~h}$ at $70^{\circ} \mathrm{C}$ and was two days at ambient air.

TOCN/PVA films: TOCN suspension was used at a concentration of $0.5 \%$. A small amount of PVA solution $(0.08 \mathrm{~g}$ in $2 \mathrm{ml}$ of water) was added to $50 \mathrm{ml}$ of TOCN suspension and stirred for one hour at room temperature at moderate speed to prevent bubble formation in the solution. The solution was poured in an aluminum dish of $90 \mathrm{~mm}$. The film was oven dried for $1 \mathrm{~h}$ at $70^{\circ} \mathrm{C}$ and set in ambient temperature conditions for 2 days.

TOCN/PVA-PPy films: The previous TOCN/PVA film was immersed in a solution of $\mathrm{FeCl}_{3}$ in $0.3 \mathrm{M}$ for $20 \mathrm{~min}$. Next, $2 \mathrm{ml}$ of pyrrole was added and distributed over the entire film. After $30 \mathrm{~min}$ of polymerization, the film was completely dark and coated with PPy particles (Figure 1). The composite was thoroughly rinsed with distilled water before being dried between two underpressure hot plates at $80^{\circ} \mathrm{C}$. The proportion of each material in the composite is shown in Table 1 . The TOCN/PVA ratio in the composite is the same as in the TOCN/PVA films. 


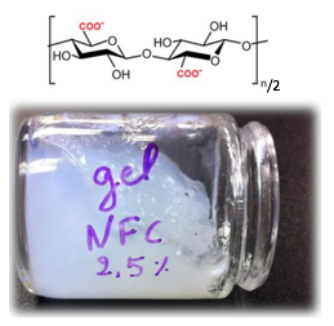

TOCN gel

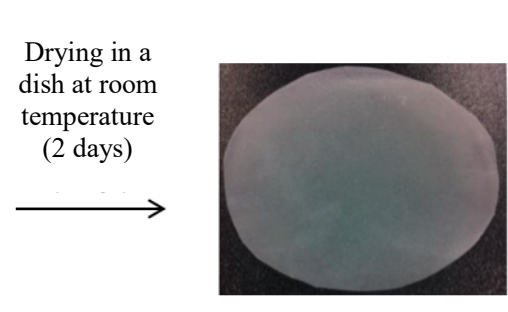

TOCN/PVA film

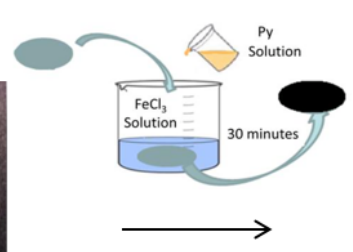

Polymerization of pyrrole with iron chloride $0,2 \mathrm{M}(30 \mathrm{~min})$

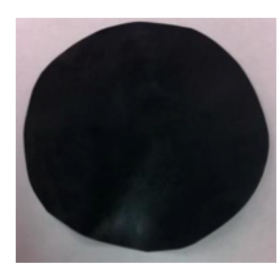

TOCN/PVA-PPy film

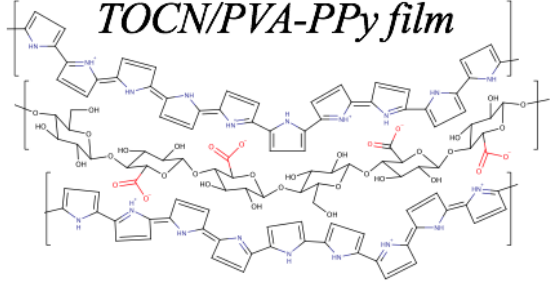

Figure 1 : Schematic illustration of coating of TOCN/PVA film by polypyrrole

Table 1. Gram $\left(\mathrm{g} / \mathrm{m}^{2}\right)$, thickness $(\mu \mathrm{m})$ and weight percentage (wt. \%) of the different materials for each film.

\begin{tabular}{lccccccc}
\hline & $\begin{array}{c}\text { TOCN } \\
(w t . \%)\end{array}$ & PVA (wt.\%) & PPy (wt.\%.) & Grams (g/m $)^{2}$ & $\begin{array}{c}\text { Thickness } \\
(\mu \mathrm{m})\end{array}$ & $\begin{array}{c}\text { Specific } \\
\text { gravity }\end{array}$ \\
\hline TOCN & 100 & - & - & $39.0 \pm 1.4$ & $31.7 \pm 1.6$ & $1.23 \pm 0.09$ \\
TOCN/PVA & $93.3 \pm 0.2$ & $6.7 \pm 0.2$ & - & $40.8 \pm 1.5$ & $34.2 \pm 2.2$ & $1.19 \pm 0.10$ \\
TOCN/PVA-PPy & $81.1 \pm 0.2$ & $5.8 \pm 0.2$ & $13.1 \pm 0.5$ & $44.4 \pm 2.3$ & $41.0 \pm 2.3$ & $1.08 \pm 0.10$ \\
\hline
\end{tabular}

\subsubsection{Characterization}

The samples were conditioned at room temperature $\left(25^{\circ} \mathrm{C}, 50 \% \mathrm{RH}\right)$ during $24 \mathrm{~h}$ before all characterizations. Weight percentage of each component was determined by sequential weighting at each step of the fabrication process (Figure 1) and reported in table 1. The film thickness was measured with scanning electron microscopy images of the cross section (obtained by a microtome) of samples by using JEOL JSM T300 microscope.

Scanning electron microscopy (SEM). The morphology of samples was obtained using scanning electron microscopy (SEM) with a JEOL JSM T300 microscope equipped with EDX (Energy-dispersive X-ray spectroscopy) analysis. Because pure PPy and TOCN/PVA-PPy are conductors, only the TOCN/PVA sample was gold-coated using an Instrumental Scientific Instrument PS-2 coating unit. Cross-sections were obtained by a microtome. The operation was conducted in secondary electron mode at a beam current of $100 \mu \mathrm{A}$ with an accelerating voltage of $15 \mathrm{kV}$.

Tensile strength. The tensile strength and elongation at break of the TOCN/PVA and TOCN/PVA-PPy were measured on a universal testing machine (Instron 4201$)$ at room temperature $\left(25^{\circ} \mathrm{C}\right.$ and $\left.50 \% \mathrm{RH}\right)$, with a gauge length of $10 \mathrm{~mm}$ and at a crosshead speed of $10 \mathrm{~mm} / \mathrm{min}$. Because our composite films are not thick enough, we did not use an extensometer for measuring the strain during the tensile test. For this reason, the elongation has been measured by the displacement of the head, and detected by motor. The average value of six replicates for each sample was taken, with each sample being 575 to $950^{\circ} \mathrm{C}$ under air at a heating rate of $15^{\circ} \mathrm{C} / \mathrm{min}$. At least six duplicates were performed. . Each sample, on average, was measured to be a size of $30 \mathrm{~mm}$ in length, $15 \mathrm{~mm}$ in width, and $0,04 \mathrm{~mm}$ in thickness.

Thermogravimetric analysis (TGA). Thermal stability of the samples was carried out by a Perkin-Elmer (Pyris Diamond) Thermoanalyzer. Samples of TOCN, TOCN/PVA and TOCN/PVA-PPy were heated in open alumina pans from 50 to $575^{\circ} \mathrm{C}$, under a nitrogen atmosphere, at a heating rate of $4^{\circ} \mathrm{C} / \mathrm{min}$. Then, samples were heated from 575 to $950^{\circ} \mathrm{C}$ under air at a heating rate of $15^{\circ} \mathrm{C} / \mathrm{min}$. Duplicates were performed.

Contact angle (CA). Contact angle measurements have been carried out on TOCN, TOCN/PVA and TOCN/PVA-PPy in order to evaluate the surface energy of the components of the composite. A drop each $(0.8 \mu \mathrm{L} \pm 0.07)$ of three probe liquids (water, formamide and 1-bromonaphthalene) was placed onto the samples. The contact angle was determined by measuring the angle between the sample surface and the tangent at the drop of the solid-liquid air point using a contact angle system OCA20 (Data Physics). At least 5 drops of each probe liquid were deposited onto each substrate and a total of 300 images were captured within $5 \mathrm{~s}$ for each drop. From the static data with pure liquids of different polarities, the dispersive and polar contributions to the surface energy were obtained using the approach proposed by Owens and Wendt (1969). ${ }^{41}$ The components are obtained by the following formula:

$$
(1+\cos (\theta)) \gamma_{L V}=2 \sqrt{ }\left(\gamma_{S}{ }^{D} \gamma_{L}^{D}\right)+2 \sqrt{ }\left(\gamma_{S}{ }^{P} \gamma_{L}{ }^{P}\right)
$$

where $\theta$ is a contact angle, $\gamma_{\mathrm{LV}}$ is the surface free energy, $\gamma_{\mathrm{S}}^{\mathrm{D}}$ and $\gamma_{\mathrm{L}}^{\mathrm{D}}$ are the dispersion components, $\gamma_{\mathrm{S}}^{\mathrm{P}}$ and $\gamma_{\mathrm{L}}^{\mathrm{P}}$ are the polar components.

Antibacterial tests. The standard AFNOR NF EN 1104 procedure and AATCC 100-1998 procedure are two antibacterial tests, the first being qualitative and the second, quantitative. Firstly, antibacterial efficiency of TOCN/PVA and TOCN/PVA-PPy was evaluated against $B$. subtilis according to the standard AFNOR NF EN 1104 procedure. ${ }^{42,43}$ Thus, we placed circular samples (100 
$\mathrm{mg}$ ) onto pre-inoculated agar (with B. subtilis) followed by incubation for 3 days at $30^{\circ} \mathrm{C}$. Determination of the zone of inhibition was calculated in triplicate.

The AATCC Test Method 100-1998 ${ }^{44}$ was used to assess the antibacterial activity of TOCN, TOCN/PVA and TOCN/PVA-PPy. This method is designed to quantitatively test the ability of textiles to inhibit the growth of microorganisms or kill them. It was adapted for our composites and tested with B. Subtilis and E. coli over a 24-hour period of contact under static conditions. All bacterial pre-inoculum cultures were grown overnight at $36^{\circ} \mathrm{C}$ in $40 \mathrm{ml}$ Nutrient Broth (NB) (horizontal shaking). The Colony-forming Unit (CFU) of bacteria pre-inoculum was determined by serial dilution at $35 \times 10^{7}$ (CFU). The bacteria preinocula was diluted with NB $20 \%$ to obtain an inoculum at $5 \times 10^{5}$ CFU. Next, $200-\mu 1$ aliquots of cell suspension (containing $5 \times 10^{5} \mathrm{CFU}$ ) were used to inoculate each $0.05 \mathrm{~g}$ composite sample by the deposition of several micro-droplets on their surface. The samples were previously laid down in $60 \mathrm{~mm}$ petri dishes that were placed, without coverings, into $90 \mathrm{~mm}$ petri dishes containing approximately $15 \mathrm{ml}$ of sterile water to avoid the drying of the paper specimens during incubation. For all materials, untreated control and treated samples, two samples were inoculated with each bacteria to determine the number of cells at the end of the antibacterial test $\left(\mathrm{CFU} \mathrm{T} \mathrm{T}_{24}\right)$. Immediately after inoculation, the number of inoculated bacteria was extracted with $25 \mathrm{ml}$ of neutralizing solution to recover inoculated bacteria (CFU $\mathrm{T}_{0}$ determination), while the petri dishes containing the other two inoculated samples were incubated overnight at $37^{\circ} \mathrm{C}$ for all bacteria. The composition of the neutralizing solution was indicated by Saini et al. (2015). ${ }^{45}$ After $24 \mathrm{~h}$ incubation, the test specimens were extracted with the neutralizing solution and the numbers of colony forming units $\left(\mathrm{CFU} \mathrm{T}_{24}\right)$ were determined. To evaluate the antibacterial efficacy of the treated samples, the CFU $\mathrm{T}_{24}$ values were used to calculate the bacterial log reduction values by the following formula:

$\log$ reduction $=\log \mathrm{CFU} \mathrm{T}_{24}$ untreated sample $-\log \mathrm{CFU} \mathrm{T}_{24}$ treated sample.

Due to the intrinsic variability of the antibacterial test results, as reported in the JIS Z 2801:2000, at least a 2 log reduction was considered necessary to claim an antibacterial activity. Two different antibacterial effects could be distinguished:

- Bacteriostatic: inhibition of bacterial growth, at least a $2 \log$ reduction with respect to an untreated sample at $\mathrm{T}_{24}\left(\mathrm{CFU} \mathrm{T}_{24}\right.$ untreated sample);

- Bactericidal: inhibition of bacterial growth and concomitant reduction of the number of inoculated bacteria (at least 2 log reduction with respect to the inoculated bacteria, $\mathrm{CFU} \mathrm{T}_{0}$ ).

Antibacterial meat tests. The composite was finally tested to demonstrate our sample effectiveness as active sterile packaging. Pork liver was chosen because its degradation is achieved more quickly and is clearly noticeable by change in color. The pieces of meat $\left(5 \mathrm{~cm}^{2}\right)$ were brought into contact with TOCN and TOCN/PVA-PPy films. The samples were closed in polyethylene plastic and were stored at room temperature for 24 hours.

\section{RESULTS AND DISCUSSION}

\subsection{Morphological structure of TOCN composite}

Scanning electron microscopy (SEM) images of film were analyzed. The SEM images suggested that the string of TOCN (Figure 2a) length ranged from few $\mu \mathrm{m}$ and width averaged the order of nanometer, which should create a dense network that would be responsible for higher mechanical properties and flexibility of the composite. In Figure $2 \mathrm{~b}$, we can see that the incorporation of a small amount of PVA has no visible influence on film morphology. TOCN/PVA film also presents a dense arrangement of fibers, where it's possible to see micro and nanofibers. In comparison, the cross-section of TOCN (Figure 2d) and TOCN/PVA films (Figure 2e) confirms that there is no apparent influence of PVA on TOCN arrangement as both cross-sections are similar. The underside is flat and TOCN are clearly organized in multiple sheet layers. However, on the upper face, the fibers have sedimented in a structure of a few $\mu \mathrm{m}$ in thickness. This situation could be explained by the fiber length distribution, as the TOCN gel (micro-fibrillated and nano-fibrillated) is composed of various lengths ranging from nanometric to micrometric scale. Thus, smaller fibers will sediment at a considerably slower rate and will be found in increased concentration in the upper section of the film.

The polymerization of pyrrole by iron chloride oxidant gives a porous structure with PPy nanoparticles (cauliflower structure). ${ }^{8}$ On Figure 2c, it is possible to see that the fibrous substrate of cellulose have completely disappeared by being covered with the conjugated polymer. If we compare to Figure $2 b$, it can be deduced that a TOCN/PVA is completely covered by a layer of PPy nanoparticles. Moreover, the structure of a TOCN/PVA film is relatively close and compact, so any pyrrole solution poured in the system will not be able to diffuse much deeper in the surface layer. For this reason, the PPy chains were mostly made only at the film's surface. The polymerization-induced adsorption process, which is made on the surface of oxidized cellulose by the chains of PPy, does not allow obtaining a uniform layer on the fiber surface. We did not have control over the agglomeration of the conjugated polymer, and the polymer chains are prone to be deposited as irregular nanoparticles or sediments. The particles are an irregular sphere and in aggregate forms. As shown in Figure 2f, a cross-section of the TOCN/PVA-PPy was performed to understand the arrangement of PPy particles on a TOCN/PVA film. The layer of PPy was visible on each side of the composite. The continuous coating of PPy was performed only on surfaces with a thickness ranging from 3 to $8 \mu \mathrm{m}$. In the middle layer, we can see the TOCN structure arranged in a sheet. Thus, the polymerization of pyrrole occurred on all surfaces of our composite supported by the reinforcement of cellulose. 


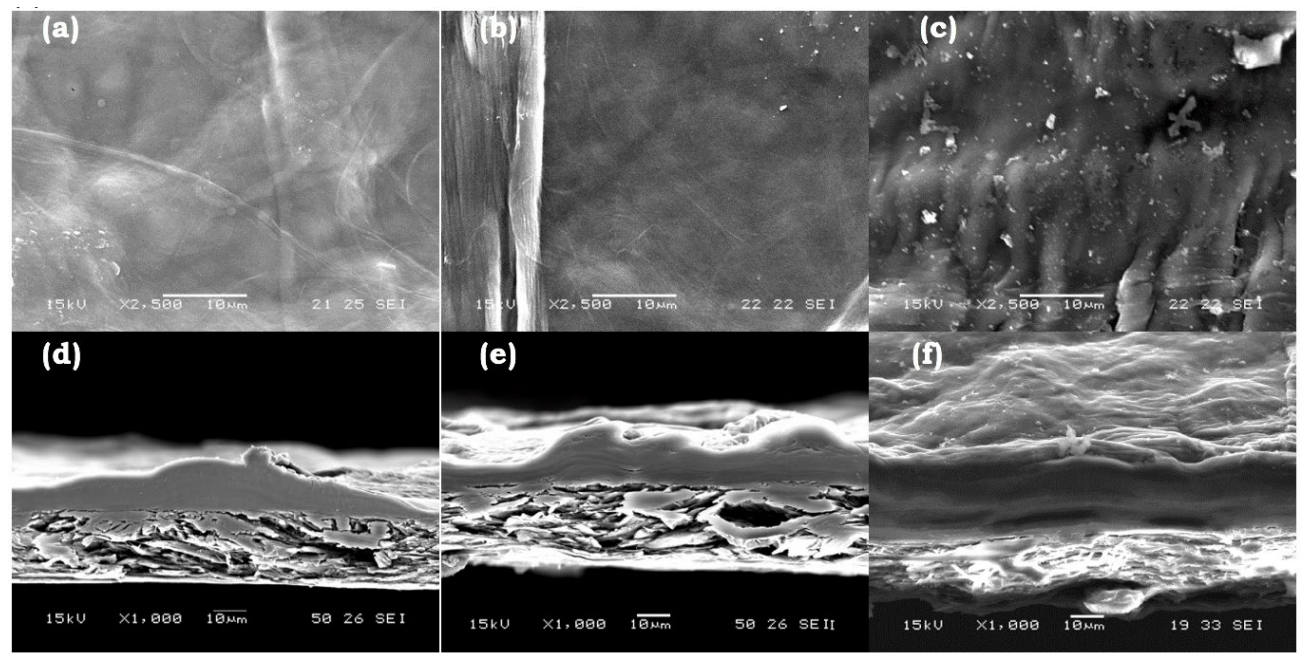

Figure 2: SEM micrograph of the TOCN (a: surface; d: cross-section), TOCN/PVA (b: surface; e: cross-section), TOCN/PVA-PPy film (c: surface; f: cross-section)

Quantitative analysis of the elements $\mathrm{C}, \mathrm{O}, \mathrm{N}, \mathrm{Cl}$ and $\mathrm{Fe}$ was performed by EDX analysis and reported in Table 2. Note that $\mathrm{Cl}$ and $\mathrm{Fe}$ elements are only residues of the pyrrole polymerization with iron chloride oxidant. Several EDX spectra of each surface and the central layer of TOCN/PVA-PPy film were acquired at different specimen areas (points and lines), and all the localizations are indicated on Figure $3 \mathrm{a}$ and $3 \mathrm{~b}$. Analysis performed on the cross-section and surface, as confirmed the presence of nitrogen on the surface. This incidence was used as an indication of the presence of the PPy since TOCN is only composed of carbon, oxygen and hydrogen. Our equipment as the possibility to acquire multiple EDX spectrum on a line and report the mean atomic composition value on a given length of sample (about $75 \mu \mathrm{m}$ ). From Table 2, the comparison of the top layer composition from line 1 and the single data point (position 3) are found to be in good agreement, thus also showing a good homogeneity of our composite. When compared to line 2 (central layer), position 4, 5 and 6 in Figure 3b, which were acquired on the surface of the composite, exhibited a strong presence of $\mathrm{N}$ (approximately $11 \mathrm{At} \%$ ), which reinforces the idea that the PPy is on the surface. As already shown with line 1 and position 3, the values of position 4, 5 and 6 also confirm the homogeneity of the coating. At position 5 , we can see that the aggregate is mainly PPy chains (low percent of oxygen).

By nature, the structure of the TOCN/PVA film is tightly closed and compact. Even if the film is immersed in liquid, very little surface swelling is occurring, thus limiting the diffusion through the thickness of the composite. Accordingly, any pyrrole solution poured in the system will not be able to diffuse much deeper than in the surface layers and is will be limited to diffusion in bulk of the solution. From the atomic composition of line 2, we have found $2.7 \%$ of nitrogen as TOCN should in principle exhibit none. It shown a small diffusion of pyrrole, most likely in the first stage of the polymerization, and as the PPy is formed, the middle layer would not be accessible anymore. For all these reason, the polymerization of PPy is mostly done only at the film surface, as confirmed by the EDX measurements.

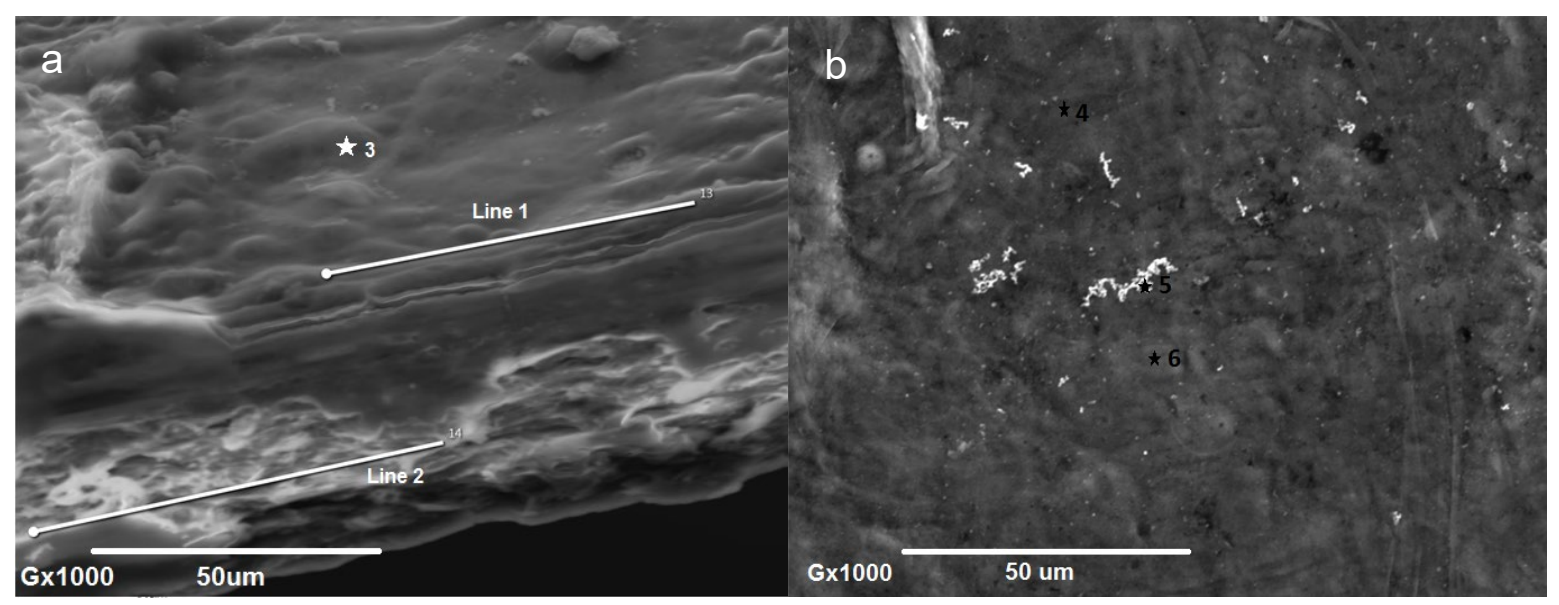

Figure 3: SEM micrograph used for EDX analysis of a cross-section (left) and surface (right) of TOCN/PVA-PPy 
Table 2: Atomic percent of element for different positions on the film

\begin{tabular}{ccccccc}
\hline & $\begin{array}{c}\text { Atomic } \\
\text { percent } \\
\text { (Total) }\end{array}$ & $\begin{array}{c}\text { Line 1 } \\
\text { (Top layer } \\
\text { average) }\end{array}$ & $\begin{array}{c}\text { Line 2 } \\
\text { (Central layer } \\
\text { average) }\end{array}$ & $\begin{array}{c}\text { Position 3 } \\
\text { (Top layer) }\end{array}$ & $\begin{array}{c}\text { Position 4 } \\
\text { (Surface) }\end{array}$ & $\begin{array}{c}\text { Position 5 } \\
\text { (Surface) }\end{array}$ \\
\hline C (At\%) & 74.1 & 72.8 & 82.9 & 71.2 & 75.2 & 79.1 \\
(Surface)
\end{tabular}

\subsection{Influence of PPy on Surface energy}

The values of the contact angle measured with the different liquids (water, formamide, 1-bromonaphtalene) and those of the calculated energy surface components are shown in Table 3.

Table 3: Contact angle $\left({ }^{\circ}\right)$, surface energy values $\left(\mathrm{mJ} / \mathrm{m}^{2}\right)$ and mechanical properties of TOCN, TOCN/PVA and TOCN/PVA-PPy.

\begin{tabular}{|c|c|c|c|c|c|c|c|c|c|}
\hline \multirow[b]{3}{*}{ TOCN } & \multicolumn{3}{|c|}{ Contact angle $\left(^{\circ}\right)$} & \multicolumn{3}{|c|}{ Surface energy $\left(\mathrm{mJ} . \mathrm{m}^{-2}\right)$} & \multicolumn{3}{|c|}{ Mechanical properties } \\
\hline & Water & Formamide & $\begin{array}{c}\text { Bromo- } \\
\text { naphtalene }\end{array}$ & total & $\begin{array}{l}\text { Dispersive } \\
\text { component }\end{array}$ & $\begin{array}{c}\text { Polar } \\
\text { component }\end{array}$ & $\begin{array}{l}\text { Stress } \\
(\mathrm{MPa})\end{array}$ & $\begin{array}{l}\text { Young's } \\
\text { Modulus } \\
(\mathrm{GPa})\end{array}$ & $\begin{array}{c}\text { Elongation } \\
\text { at break }(\%)\end{array}$ \\
\hline & $54.5 \pm 3.8$ & $49.7 \pm 1.9$ & $35.5 \pm 1.3$ & 53.4 & 36.6 & 16.8 & $53.4 \pm 3.8$ & $3.4 \pm 0.6$ & $2.6 \pm 0.6$ \\
\hline TOCN/PVA & $62.0 \pm 2.3$ & $46.1 \pm 3.6$ & $32.6 \pm 2.0$ & 49.8 & 37.7 & 12.1 & $99.4 \pm 18.0$ & $3.7 \pm 0.5$ & $5.6 \pm 1.5$ \\
\hline $\begin{array}{l}\text { TOCN/PVA- } \\
\text { PPy }\end{array}$ & $83.0 \pm 2.2$ & $55.0 \pm 2.1$ & $39.1 \pm 3.0$ & 38.4 & 35.0 & 3.4 & $48.2 \pm 6.0$ & $3.5 \pm 0.6$ & $2.6 \pm 0.4$ \\
\hline
\end{tabular}

The apparent contact angles for all liquids with TOCN/PVA-PPy are larger than those with TOCN and TOCN/PVA. Pure TOCN film is vulnerable to water $\left(25^{\circ}\right)$ as shown by Jung et al. ${ }^{46}$ TOCN showed the typical high water affinity associated with a fast decrease in the contact angle $\left(54^{\circ}\right)$. However, the hydrophilic character is not as strong as for pure TOCN. This result can be explained by the structure of the film, which is very dense, thus causing the tight knit fiber to slow the wettability of the film. The addition of PPy gave the expected decrease in hydrophilic character $\left(83^{\circ}\right)$, which is explained by the presence of the aliphatic chain of the particles of PPy. The uncontrolled coating shows a decrease of hydrophilic character compared to the cellulose/PPy composite that is obtained by controlling the polymerization of pyrrole. ${ }^{21}$ The thickness of the PPy layer is important in order to obtain high hydrophobic character. With different solvents, we noticed that the PPy layer played the role of protection. However, the wetting of the composite is still possible, even if the presence of PPy chains help to slow this process.

The surface energy of the samples as determined according to Owens/Wendt theory by contact angle measurement is shown in Table 3. The surface energy decreases with decreasing hydrophilic character. As expected, the decrease in the surface energy after polymerization was essentially due to the reduction in its polar component because of the replacement of the surface hydroxyl groups by the non-polar aliphatic chains (PPy chains).

\subsection{Mechanical and thermal properties}

The mechanical properties of TOCN, TOCN/PVA and the TOCN/PVA-PPy are shown in Table 3. These results are given after a clear breaking of the composite. It is important to note that the tensile results of pure PPy are not present in the table due to the poor mechanical properties of the PPy film. This is already a clear advantage of TOCN-PPy composite. Indeed, TOCN allows fabrication of highly performant self-standing film of PPy as already studied for conductive applications. ${ }^{32}$

The strength of the TOCN/PVA can be attributed to the strongest interactions, inter- and intra-molecular hydrogen bonding, occurring in the entangled structure of the cellulose nanofibers. The results indicate that the tensile strength and the elongation at break (\%) slightly decreased with the presence of PPy in the composite films. The coating of PPy increased the brittleness and decreased the elongation at break. Therefore, the decrease of both tensile strength and elongation at break can be associated with the presence of surface PPy nanoparticles interfering with the TOCN chains and reducing their interactions. In this context, Young's modulus values of the composite films confirmed a higher stiffness of the composite, which was conferred by the presence of the PPy. Results presented in Table 3 when compared to the specific gravity of the same composites (Table 1), show that the even if the TOCN/PVA-PPy composite is about $12 \%$ lower in density, it almost exhibit the same mechanical properties as TOCN alone. The addition of PVA to TOCN, slightly lower the specific gravity but it is not meaningful in respect to the standard deviation. Thus, the increase shown in Table 3 is from increased crosslinking between TOCN fibers. This synthesis process (PPy coating of TOCN/PVA film) demonstrate better results than those obtained by Jradi et al. ${ }^{32}$ with a in situ polymerization of pyrrole on cellulose fiber, in a solution. Moreover, our composite has good flexible properties because it can be bent by up to 180 degrees or even wound up.

In conclusion, the improved mechanical properties of TOCN/PVA-PPy compared to PPy that were observed could be explained by the contribution of the excellent mechanical properties of the TOCN. However, the decreased mechanical behavior could be attributed to the weakened inter- and intramolecular hydrogen bonding of cellulose nanofibers caused by the incorporation of PPy nanoparticles.

The thermogravimetric curves of TOCN, TOCN/PVA and TOCN/PVA-PPy films are presented in Figure 4. Both materials contained a few layers of moisture which were eliminated at $110^{\circ} \mathrm{C}$. As shown in the thermogram curve, pure TOCN appeared to 
decompose between $200^{\circ} \mathrm{C}$ and $340^{\circ} \mathrm{C}$ where the corresponding weight loss was attributed to the destruction of the crystalline region of the TOCN and decomposition of amorphous TOCN into a monomer of D-glucopyranose. In comparison with TG curves of TOCN and TOCN/PVA, thermal degradation of film presented an identical behavior with the presence of PVA, as shown in Figure 4. The proportion of PVA in the film was too small to have a real influence on the thermal degradation at low temperatures. Nevertheless, it is possible to see that the TOCN/PVA film presents a slightly higher stability for two at beyond $600^{\circ} \mathrm{C}$.

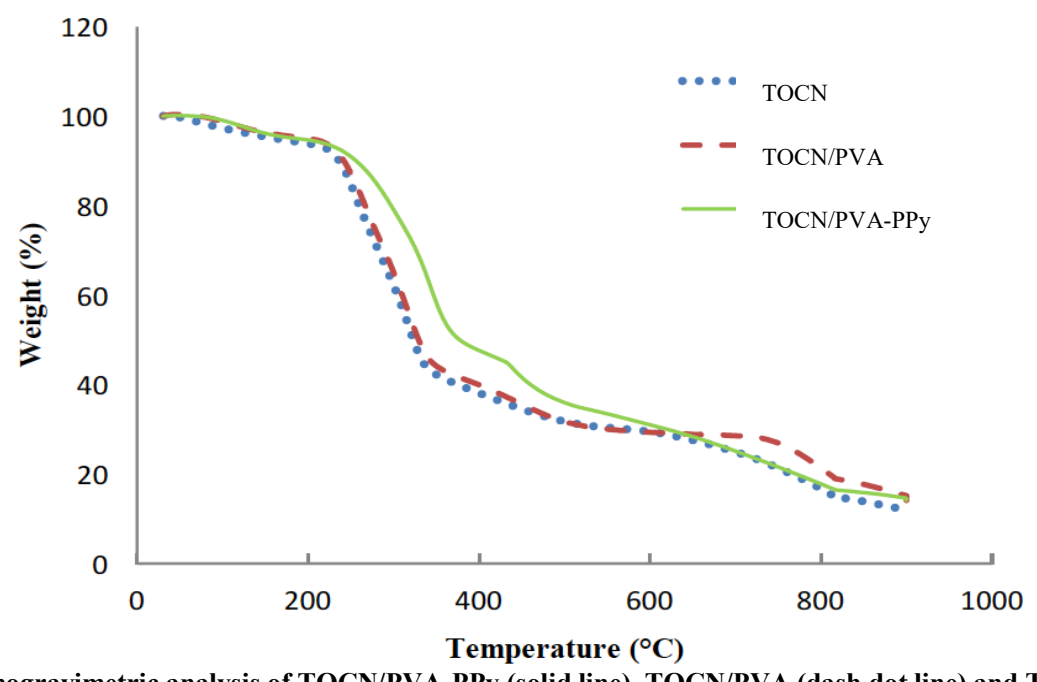

Figure 4: Thermogravimetric analysis of TOCN/PVA-PPy (solid line), TOCN/PVA (dash dot line) and TOCN (dot line).

It is possible to observe a slight improvement to the thermal stability of the TOCN/PVA-PPy over TOCN/PVA and TOCN that could be attributed to the thin layer of PPy which offers thermal processing advantages. This improvement could potentially be increased further if a thicker PPy layer was deposed. The interactions between TOCN/PVA and PPy could explain the shift observed in the thermal degradation temperature of TOCN from $200^{\circ} \mathrm{C}$ (TOCN/PVA film) to $240^{\circ} \mathrm{C}$ (TOCN/PVA-PPy). The first weight loss corresponds to the thermal decomposition of cellulose nanofibers at low temperatures and at $440^{\circ} \mathrm{C}$ while the second one is attributed to the degradation process of the PPy matrix. After, there is a gradual decrease in weight in the measured temperature range (up to $900^{\circ} \mathrm{C}$ ). The decomposition of TOCN/PVA-PPy followed a similar trend as the TOCN film. Thus, the thermal stability of the composite seems to be increased until $600^{\circ} \mathrm{C}$ by the presence of PPy.

\subsection{Antibacterial Activity of TOCN/PPy composite}

Recently, excellent antibacterial activity against Gram-positive and Gram-negative bacteria was achieved by polymerization of pyrrole on dextrin. ${ }^{4}$ The antibacterial actions of dextrin PPy-coated fabrics were attributed to the interaction between the positive charges on the PPy chain and the bacteria cell wall. In this study, the antibacterial activity was evaluated against Gram-positive $B$. Subtilis and Gram-negative E. coli. TOCN/PVA film was used as a control to confirm that the antibacterial property was indeed provided by the PPy coating. First, a qualitative test according to the AFNOR NF EN 1104 standard procedure was performed against $B$. Subtilis. As seen in Figure 5a, a homogenous bacteria growth on the nutritive agar was found despite being in contact with the TOCN/PVA film. However, in contact with the TOCN/PVA-PPy, a clear inhibition effect of the bacteria growth on agar can be observed (Figure 5b). These results also suggest that minimal release or diffusion of PPy particles was achieved in spite of a long contact period (3 days) because the contact delimitation of the composite film with the agar is clearly visible. A leaching analysis was performed and showed that the composite releases only $0.2 \times 10^{-3}\left( \pm 5.2 \times 10^{-6}\right) \mathrm{mol} / \mathrm{L}$ of PPy after being submerged in water for 48 hours. Thus, the PPy demonstrates antibacterial activity in contact with the bacteria while being immobilized in the composite. This first test confirms that our TOCN/PVA-PPy exhibits antibacterial activity due to the presence of PPy on the surface.

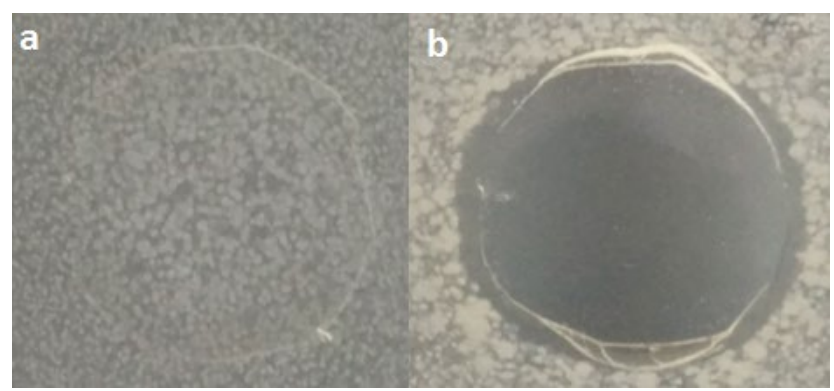

Figure 5: Antibacterial activity of TOCN/PVA (a) and TOCN/PVA-PPy (b) against B. Subtilis using disk diffusion method.

A second test, according to AATCC Method 100-1998, was used to quantitatively assess the antibacterial potential of the TOCN/PVA-PPy. The results are shown in Figure 6 presented in the total log Colony-forming Unit. 


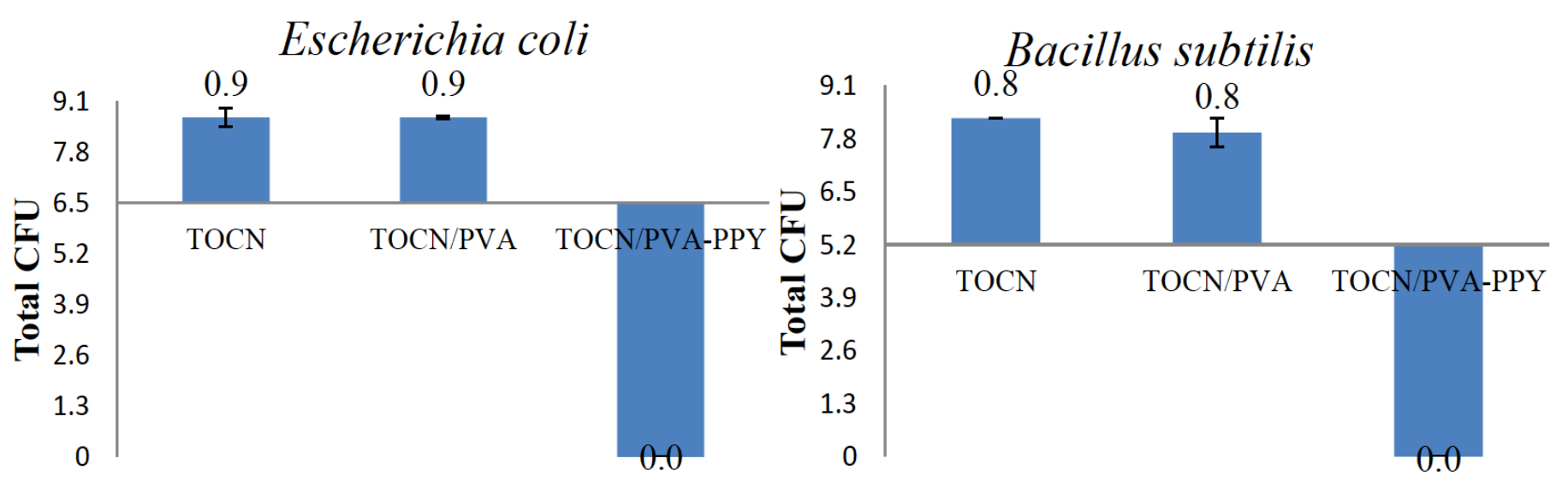

Figure 6: Antibacterial activities assessment of TOCN, TOCN/PVA and TOCN/PVA-PPy film with B. Subtilis and E. coli using the ATCC method.

This test was performed with E. coli and B. Subtilis. In the presence of the TOCN and TOCN/PVA controls, the two bacterial strains had continued to grow for $24 \mathrm{~h}$. For the film made of TOCN only, we see an increase of $2.2 \log$ CFU in the presence of $E$. Coli (baseline at 6.5) and $3.1 \log$ CFU for B. Subtilis (baseline at 5.2), thus showing strong conditions for bacterial growth. At the same time, the two bacterial strains have grown by $2.2 \log$ CFU (E. Coli) and $2.8 \log$ CFU (B. Subtilis) on TOCN/PVA film. These results reveal that the TOCN and TOCN/PVA film did not have an inhibitory effect against these microorganisms. Further, when the bacteria were placed in contact with the TOCN/PVA-PPy, total growth inhibition could be observed (Fig 5). The number of bacterial colonies even exhibits a decrease, therefore suggesting a bactericidal effect (-5.2 log CFU for B. Subtilis and -6.5 log CFU for $E$. Coli over respective baseline). All bacteria have been destroyed in contact with the PPy chains. The electrostatic interaction established between our composite and bacteria provokes the bacterial cell death. These results confirm that a good antibacterial activity against Gram-negative bacteria and Gram-positive bacteria is found with PPy in the composite, as also demonstrated by Zare et $a l .{ }^{3}$ and more recently by Silva Jr et al. ${ }^{5}$ It can be deduced that TOCN/PVA-PPy with a polycationic backbone can disrupt the microbial cell membranes by stopping cellular respiration. Moreover, the character of electron donorelectron acceptor of PPy chains played an important part in bacterial adhesion to a solid surface, which is a crucial step in the biofilm process. ${ }^{47,48}$ Similar antibacterial effects were reported in literature concerning the PPy-g-CS copolymer. ${ }^{11}$

The values obtained for the antibacterial activity of this PPy nanocomposite represented an interesting finding regarding all bacteria tested in the context of an active sterile packaging. Some further work against bacteria such as Staphylococcus aureus and Staphylococcus epidermidis could even make possible the incorporation of TOCN/PVA-PPy into latex gloves, which could create a strong antibacterial barrier between the surgeon's hands and the patient's body, or even for packaging surgical instruments. Clearly, these applications need to be further investigated.

\subsection{Antibacterial meat test}

To demonstrate the effectiveness of our samples as sterile packaging, we performed a test with liver. The liver was chosen as an excellent subject because it quickly demonstrates a color change due to bacteria development when the cold chain is broken, thus making it an effective indicator as to the quality of our sterile packaging. These tests were carried out on liver for 24 hours at room temperature. The results are shown in Figure 7. For 24 hours, the cold chain had been cut off and it is possible to see that in the presence of cellulose film, the liver presents green traces indicative of bacteria development. However, the piece of liver in contact with the film TOCN/PVA-PPy appears fresh and without bacteria. Indeed, there was no trace of the greenish color typical of bacteria development, making the TOCN/PVA-PPy film a most promising candidate as an active sterile packaging for food or surgical applications.

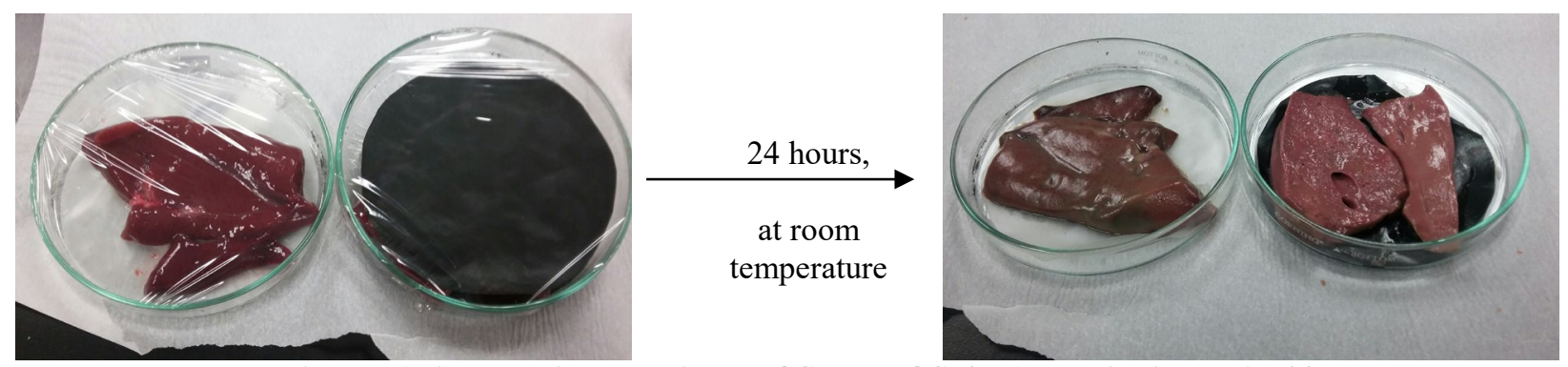

Figure 7: Active packaging evaluation on TOCN and TOCN/PVA-PPy with liver during $24 \mathrm{~h}$.

\section{CONCLUSIONS}

A flexible TOCN/PVA-PPy film was prepared by chemical polymerization of pyrrole in surface contact of TOCN. The SEM and EDX characterizations have shown that PPy particles totally coated the surface of the TOCN/PVA film. The results concerning the strong properties of the composite revealed a significant effect of TOCN/PVA substrate in the improvement of the mechanical properties of PPy. The addition of PPy allowed an increase in hydrophobic character of the composite. 
Additionally, the observed antibacterial properties suggest that TOCN/PVA-PPy has strong antibacterial activity and can be used further for application as an effective polymeric antibacterial agent. PPy was successful in killing various bacteria that contacted the coated surface. As suggested by our results, the higher hydrophobicity of the PPy composite could also enhance the hypothesis that bacteria grip and growth on the surface would be more difficult. These discoveries concerning micro-organism inhibition exhibit promise for active sterile packaging, such as that employed for surgical instruments.

\section{ACKNOWLEDGMENTS}

Fonds de recherche du Québec - Nature et technologies (FRQNT), Centre de recherche sur les matériaux renouvelables (CRMR), Laboratoire Génie des procédés papetiers (LGP2) and the Natural Science and Engineering Research Council of Canada (NSERC). LGP2 is part of the LabEx Tec 21 (Investissements d'Avenir - grant agreement $n^{\circ}$ ANR-11-LABX-0030) and of the Énergies du Futur and PolyNat Carnot Institutes (Investissements d'Avenir - grant agreements n ${ }^{\circ}$ ANR-11-CARN-007-01 and ANR-11-CARN-030-01). This research was made possible thanks to the facilities of the TekLiCell platform funded by the Région of Rhône-Alpes (ERDF: European regional development fund).

\section{REFERENCES}

1 - Li, X.; Wang, Y.; Yang, X.; Chen, J.; Fu, H.; Cheng, T. Conducting Polymers in Environmental Analysis. Trends Anal. Chem. 2012, 39, 163-179.

2 - Reungurai, A.; Promjun, A.; Ouajai, W.P.; Ouajai, S. Synthesis of Highly Conductive Polypyrrole Nanoparticles via Microemulsion Polymerization. J. Met. Mater. Miner. 2008, 18, 27-31.

3 - Zare, E.N.; Lakouraj, M.M.; Mohseni, M. Biodegradable Polypyrrole/Dextrin Conductive Nanocomposite: Synthesis, Characterization, Antioxidant and Antibacterial Activity. Synth. Met. 2014, 187, 9-16.

4 - Molina, J.; Fernández, J.; Del Río A.I; Lapuente, R.; Bonastre, J.; Cases, F. Stability of Conducting Polyester/Polypyrrole Fabrics in Different pH Solutions, Chemical and Electrochemical Characterization. Polym. Degrad. Stab. 2010, 95, 2574-2583.

5 - Silva Jr., F.A.G; Quieroz, J.C.; Macedo, E.R.; Fernandes, A.W.C.; Freire, N.B.; Da Costa, M.M.; De Oliveira, H.P. Antibacterial behavior of polypyrrole: The influence of morphology and additives incorporation. Mater. Sci. Eng.: C. 2016, 62, 317-322.

6 - Wang, X.; Gu, X.; Yuan, C.; Chen, S.; Zhang, P.; Zhang, T.; Yao, J.; Chen, F.; Chen, G. Evaluation of Biocompatibility of Polypyrrole In Vitro and In Vivo. J. Biomed. Mater. Res-A. 2004, 68, 411-422.

7 - Chougulea, M.A.; Pawar, S.G.; Godse, P.R.; Mulik, R.N.; Sen, S.; Patil, V.B. Synthesis and Characterization of Polypyrrole (PPy) Thin Films. Soft. Nanosci. Lett. 2011, 1, 6-10.

8 - Shinde, S.; Gund, G. Morphological Modulation of Polypyrrole Thin Films Through Oxidizing Agents and Their Concurrent Effect on Supercapacitor

Performance. Electrochim. Acta. 2014, 119, 1-10.

9 - Sangawar, V.S.; Moharil, N.A. Study of Electrical, Thermal and Optical Behavior of Polypyrrole Filled PVC: PMMA Thin Film Thermoelectrets. Chem. Sci. Trans. 2012, 2, 447-455.

10 - Dall'Acqua, L.; Tonin, C.; Peila, R.; Ferrero, F; Catellani, M. Performances and Properties of Intrinsic Conductive Cellulose-Polypyrrole Textiles. Synth. Met. 2004, 146, 213-221.

11 - Cabuk, M.; Alan, Y.; Yavuz, M.; Unal, H.I. Synthesis, Characterization and Antimicrobial Activity of Biodegradable Conducting Polypyrrole-Graft-Chitosan Copolymer. Appl. Surf. Sci. 2014, 318, 168-175.

12 - Cucchi, I.; Boschi, A.; Arosio, C.; Bertini, F.; Freddi, G.; Catellani, M. Bio-Based Conductive Composites: Preparation and Properties of Polypyrrole (PPy)Coated Silk Fabrics. Synth. Met. 2009,159, 246-253.

13 - De Adhikari, A.; Oraon, R.; Tiwari, S.K.; Lee, J.H.; Nayak, J.C. Effect of waste cellulose fibres on the charge storage capacity of polypyrrole and graphene/polypyrrole electrodes for supercapacitor application. RSC Adv., 2015, 5, 27347-27355.

14 - Ding, C.; Qian, X.; Yu, G.; A Dopant Effect and Characterization of Polypyrrole-Cellulose Composites Prepared by In Situ Polymerization Process. Cellulose. 2010, 17, 1067-1077.

15 - Sasso, C.; Zeno, E.; Petit-Conil, M.; Chaussy, D.; Belgacem, M.N.; Tapin-Lingua, S.; Beneventi, D. Highly Conducting Polypyrrole/Cellulose Nanocomposite Films with Enhanced Mechanical Properties. Macromol. Mater. Eng. 2010, 295, 934-941.

16 - Carlsson, D. O.; Mihranyan, A.; Strømme, M.; Nyholm, L. Tailoring Porosities and Electrochemical Properties of Composites Composed of Microfibrillated Cellulose and Polypyrrole. RSC Adv. 2014, 4, 8489-8497. 
17 - Olsson, H.; Nyström, G.; Strømme, M.; Sjödin, M.; Nyholm, L. Cycling Stability and Self-Protective Properties of a Paper-Based Polypyrrole Energy Storage Device. Electrochem Commun 2011, 13, 869-871.

18 - Mihranyan, A.; Nyholm, L.; Garcia-Bennett, A.E.; Strømme, M. A Novel High Specific Surface Area Conducting Paper Material Composed of Polypyrrole and "Cladophora" Cellulose. J. Phys. Chem. B. 2008, 112, 12249-12255.

19 - Olsson, H.; Carlsson, D.O.; Nyström, G.; Sjödin, M.; Nyholm, L.; Strømme, M. Influence of the Cellulose Substrate on the Electrochemical Properties of Paper-based Polypyrrole Electrode Materials. J. Mater. Sci. 2012, 47, 5317-5325.

20 - Carlsson, D.O.; Sjödin, M.; Nyholm, L.; Strømme, M. A Comparative Study of the Effects of Rinsing and Aging of Polypyrrole/Nanocellulose Composites on Their Electrochemical Properties. J. Phys. Chem. B. 2013, 117, 3900-10.

21 - Turbak, A.F.; Snyder, F.W.; Sandberg, K.R. Microfibrillated Cellulose, a New Cellulose Product: Properties, Uses and Commercial Potential. J. Appl. Polym. Sci. 1983, 28, 815-827.

22 - Siqueira, G.; Bras, J.; Dufresne, A. Cellulosic Bionanocomposites: a Review of Preparation, Properties and Applications. Polym. 2010, 2, 728-765.

23 - Lavoine, N.; Desloges, I.; Dufresne, A.; Bras, J. Microfibrillated Cellulose - Its Barrier Properties andAapplications in Cellulosic Materials: A Review. Carbohydr. Polym. 2012, 90, 735-764.

24 - Pääkkö, M.; Ankerfors, M.; Kosonen, H.; Nykänen, A.; Ahola, S.; Österberg, M. Enzymatic Hydrolysis Combined with Mechanical Shearing and HighPressure Homogenization for Nanoscale Cellulose Fibrils and Strong Gels. Biomacromol. 2007, 8, 1934-1941.

25 - Iwamoto, S.; Nakagaito, A.N.; Yano, H. Nano-fibrillation of Pulp Fibers for the Processing of Transparent Nanocomposites. Appl. Phys. A. 2007, 89, 461-466. 26 - Saito, T.; Isogai, A. TEMPO-Mediated Oxidation of Native Cellulose. The Effect of Oxidation Conditions on Chemical and Crystal Structures of the WaterInsoluble Fractions. Biomacromol. 2004, 5, 1983-1989.

27 - Paquin, M.; Loranger, E.; Hannaux, V.; Chabot, B.; Daneault, C. The Use of Weissler Method for Scale-Up a Kraft Pulp Oxidation by TEMPO-Mediated System from a Batch Mode to a Continuous Flow-Through Sonoreactor. Ultrason Sonochem. 2013, 20, 103-8.

28 - Rattaz, A.; Mishra, S.; Chabot, B.; Daneault, C. Cellulose Nanofibres by Sonocatalysed-TEMPO-Oxidation. Cellulose. 2011, 18, 585-593.

29 - Aulin, C.; Gällstedt, M.; Lindström, T. Oxygen and Oil Barrier Properties of Microfibrillated Cellulose Films and Coatings. Cellulose. 2010, $17,559-574$.

30 - Syverud, K.; Stenius, P. Strength and Barrier Properties of MFC Films. Cellulose. 2009, 16, 75-85.

31 - Missoum, K.; Sadocco, P.; Causio, J.; Belgacem, M.N.; Bras, J. Antibacterial Activity and Biodegradability Assessment of Chemically Grafted Nanofibrillated Cellulose. Mater. Sci. Eng. 2014, 45, 477-483.

32 - Jradi, K.; Bideau, B.; Chabot, B.; Daneault, C. Characterization of Conductive Composite Films Based on TEMPO-Oxidized Cellulose Nanofibers and Polypyrrole. J. Mater. Sci. 2012, 47, 3752-3762.

33 - Luong, N.D; Korhonen, J.T.; Soininen, A.; Ruokolainen, J.; Johansson, L.S.; Seppälä, J. Processable Polyaniline Suspensions Through In Situ Polymerization onto Nanocellulose. Eur. Polym. J. 2013, 49, 335-344.

34 - Jabbour, L.; Chaussy, D.; Eyraud, B.; Beneventi, D. Highly Conductive Graphite/Carbon Fiber/Cellulose Composite Papers. Comp. Sci. Technol. 2012, 72, 616-623.

35 - Bober, P.; Liu, J.; Mikkonen, K. S.; Ihalainen, P.; Pesonen, M.; Plumed-Ferrer, C.; von Wright, A.; Lindfors, T.; Xu, C.; Latonen, R. M. Biocomposites of nanofibrillated cellulose, polypyrrole, and silver nanoparticles with electroconductive and antimicrobial properties. Biomacromolecules. 2014, 15, 3655-3663.

36 - Nathan, C. Antibiotics at the Crossroads. Nature. 2004, 431, 899-902.

37 - Wang, C-C.; Yang, F-L.; Liu, L-F.; Fu, Z-M.; Xue, Y. Hydrophilic and antibacterial properties of polyvinyl alcohol/4-vinylpyridine graft polymer modified polypropylene non-woven fabric membranes. J. Membrane Sci. 2009, 345 (1-2), 223-232.

38 - Zhua, D.; Cheng, H.; Li, J.; Zhang, W.; Shen, Y.; Chen, S.; Ge, J.; Chen, S. Enhanced water-solubility and antibacterial activity of novel chitosan derivatives modified with quaternary phosphonium salt. Mater. Sci. Eng.: C. 2016, 61 (1), 79-84.

39 - Regiel-Futyra, A.; Kus-Liśkiewicz, M.; Sebastian, V.; Irusta, S.; Arruebo, M.; Stochel, G.; Kyzioł, A. Development of Noncytotoxic Chitosan-Gold Nanocomposites as Efficient Antibacterial Materials. ACS Appl. Mater. Interfaces, 2015, 7 (2), 1087-1099. 
40 - Simonocic, B.; Tomsic, B. Structures of novel antimicrobial agents for textiles. Text. Res. J. 2010, 80, $1721-1737$.

41 - Owens, D.; Wendt, R. Estimation of the Surface Free Energy of Polymers. J. Appl. Polym. Sci. 1969, 13, $1741-1747$.

42 - AFNOR, in: AFNOR (Ed.), Papier et carton destinés à entrer en contact avec des denrées alimentaires, Détermination du transfert des constituants antimicrobiens, 2005, Vol. NF EN 1104, pp. 10.

43 - Lavoine, N.; Desloges, I.; Manship, B.; Bras, J. Antibacterial Paperboard Packaging Using Microfibrillated Cellulose. J Food Sci Technol. 2015, 52, 5590-600. 44 - Elegir, G.; Kindl, A.; Sadocco, P.; Orlandi, M. Development of Antimicrobial Cellulose Packaging Through Laccase-Mediated Grafting of Phenolic Compounds. Enzyme Microb. Tech. 2008, 43, 84-92.

45 - Saini, S.; Belgacem, N.; Mendes, J.; Elegir, G.; Bras, J. Contact Antimicrobial Surface Obtained by Chemical Grafting of Microfibrillated Cellulose in Aqueous Solution Limiting Antibiotic Release. ACS Appl Mater Interfaces. 2015, 7, 18076-85.

46 - Jung, Y. H.; Chang, T-H.; Zhang, H.; Yao, C.; Zheng, Q.; Yang, V.W.; Mi, H.; Kim, M.; Cho, S.J.; Park, D-W.; Jiang, H.; Lee, J.; Qiu, Y.; Zhou, W.; Cai, Z.; Gong, S.; Ma, Z. High-Performance Green Flexible Electronics Based on Biodegradable Cellulose Nanofibril Paper. Nat Commun. 2015, 6, 7170.

47 - Henriques, M.; Azeredo, J.; Oliveira, R. Adhesion of Candida Albicans and Candida Dubliniensis to Acrylic and Hydroxyapatite. Colloids Surf. B: Biointerfaces. 2004, 33, 235-242.

48 - Van Oss, C.J. Acid-Base Interfacial Interactions in Aqueous Media. Colloids Surf. A: Physicochem. Eng. Aspects. 1993, 78, 1-6. 